\title{
Europäisches Privatrecht und Methode
}

\author{
Entwurf einer rechtsvergleichend gewonnenen juristischen Methodenlehre
}

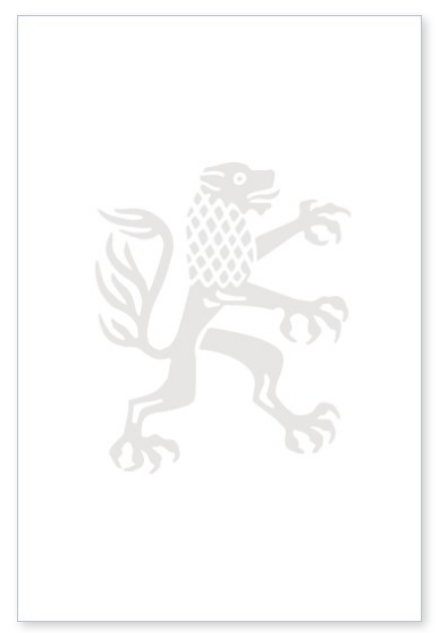

2009. XXXII, 496 Seiten. StudIPR 224

ISBN 978-3-16-151409-8

DOI 10.1628/978-3-16-151409-8

eBook PDF $94,00 €$
Aufgrund der fortschreitenden Europäisierung des Privatrechts rückt die Methodenlehre des Europäischen Privatrechts stärker in den Mittelpunkt rechtstheoretischen Denkens. Vor diesem Hintergrund erarbeitet Thomas Henninger rechtsvergleichend methodische Prinzipien des Europäischen Privatrechts. Zunächst untersucht er die existierenden Methodenlehren in den wichtigsten Ländern Europas insbesondere in Deutschland, der Schweiz, Frankreich, Großbritannien und am EuGH. Dabei legt er jeweils die gesetzlichen Methodennormen, historische Entwicklung, exemplarische Urteile, Rechtsprechung, wissenschaftliche Lehre und das methodische Selbstverständnis der Richter zu Grunde. Durch den Vergleich mit weiteren deutschsprachigen, romanischen, angloamerikanischen, skandinavischen und osteuropäischen Rechtsordnungen entsteht ein Gesamtbild der Methodenlehre in Europa.

Im normativen Teil arbeitet der Autor die gemeinsamen Prinzipien einer Methodenlehre der europäischen Privatrechte heraus und stellt Lösungsansätze für eine europäische Methodenlehre des Privatrechts vor. Dabei werden die Funktionsweise der jeweiligen methodischen Instrumente beleuchtet und deren Vor- und Nachteile abgewägt. Ein zentraler Punkt ist dabei der Vergleich der Methode kontinentaler Zivilrechtskodifikationen mit der präjudiziengestützten Fallrechtsmethodik in England und die Darstellung gemeinsamer Prinzipien. Abschluss des Buches bildet eine Methodennorm, welche - vergleichbar mit Art. 1 des schweizerischen Zivilgesetzbuches - die Tätigkeit des Richters in einem europäisch geprägten Privatrecht definiert.

Thomas Henninger Geboren 1976; Studium der Rechtswissenschaft in Freiburg i.Br., Grenoble und Berlin; 2005 DEA in Genf; 2008 Promotion in Genf; Referendar am OLG München.

Jetzt bestellen:

https://mohrsiebeck.com/buch/europaeisches-privatrecht-und-methode-9783161514098?no_cache=1

order@mohrsiebeck.com

Telefon: +49 (0)7071-923-17

Telefax: $+49(0) 7071-51104$ 